\title{
PART OF CD68+ MACROPHAGES IN THE CLEARENCE OF APOPTOTIC BODIES IN HUMAN METANEPHROS
}

\author{
Běla Erdösová*, Libuše Hlávková, Jiřina Procházková, Václav Lichnovský
} Department of Histology and Embryology, Medical Faculty of Palacký University, 77515 Olomouc, Czech Republic;
e-mail: erdos@tunw.upol.cz

Received: September 25, 2002

Key words: Macrophages / Apoptosis / Nephrogenesis

According to recent research on mice, less on human material, cells responsible for clearing apoptotic cells away during development are, besides non-professional phagocytes, also tissue-fixed macrophages. The aim of our work was the determination of macrophage role in the phagocytosis of apoptotic bodies in neogenous zone of human metanephros. Histologicaly normal kidneys were collected from embryos and fetuses ranging from the $8^{\text {th }}-28^{\text {th }}$ week of IUD. These tissues were routinely processed. In the first step we detected CD68 + cells by means of standard indirect three-step immunohistochemical method having used MAb NCL-CD68-KP1 (macrophage marker) to find out whether such cells are actually present. In the second step tissue sections were labelled by double-staining principle (TUNEL technique for the detection of apoptosis and above mentioned macrophage marker) to judge co-localization of these two items. The slides were observed by using immersion objective and the amount of apoptotic cells was expressed in percents. CD68+ macrophages appeared dispersely as single cells or small groups in all the ages studied. According to our results, CD68+ macrophages phagocytose 37-75\% of apoptotic cells present in neogenous zone and the number of engulfed apoptotic cells increases in the $12^{\text {th }}$ week of the IUD, i.e. in the early fetal period and later it merely fluctuates.

\section{INTRODUCTION}

One of the ways, by which programmed cell death (PCD) is realized, is called apoptosis. It belongs, along with proliferation and differentiation, to the vital processes involved in the IUD. The majority of research works deal with the first two phases (induction and execution of PCD) and only few have focused on the third phase (degradation of the cells having undergone PCD), mostly on murine material. The maintenance of the integrity of the cell membrane, even after the decay of the cell to apoptotic bodies, is the reason for the absence of inflammation that is in contradiction to necrosis ${ }^{1}$. Phagocytosis is initiated by the exposure of phosphatidylserine and vitronectin receptors on the plasma membrane of macrophages ${ }^{2,3}$. There are also other candidates of non-professional phagocytes recruiting from neighbouring epithelial cells, fibroblasts ${ }^{4,5}$, endothelial cells of embryonal blood vessels ${ }^{6}$. Our intention was to shed light on the involvement of $\mathrm{CD}+$ macrophages in the neogenous zone of human metanephros during nephrogenesis by means of doublestaining method (TUNEL technique and the detection of CD68+ cells in one section). This method has been recently introduced into the common practice for the more precise evaluation of co-localization of either two phenomenons or proteins.

\section{MATERIAL AND METHODS}

Histologicaly normal kidneys were collected from 7 embryos and fetuses ranging from the $8^{\text {th }}-28^{\text {th }}$ week of IUD. Tissue samples were fixed in metacarn and processed by routine paraffin technique. The first step was the detection of CD68+ cells by means of standard indirect three-step immunohistochemical method having used MAb-CD68-KP1 (Novocastra Lab. Ltd.) to verify their presence in neogenous zone during embryonic and early fetal development. The antigen CD68 is an intracellular glycoprotein localized on lyzosomal membranes of macrophages, monocytes, neutrophils and large lymphocytes.

In the second step we detected macrophages and apoptotic cells by means of double-staining method. After standard deparaffination and rehydration of section, quenching of endogenous peroxidase by $\mathrm{H}_{2} \mathrm{O}_{2}$, and microwave pre-treatment were performed. Then TUNEL reaction for the detection of apoptotic cells followed (fluoresceination of DNA fragments by terminal deoxynucleotidyl transferase together with binding of conjugate of anti-fluorescein and alkaline phosphatase (Roche). Before the incubation of samples with primary antibody to CD68 (Novocastra Lab.Ltd.), the blocking of non-specific binding sites with $1 \%$ BSA was being performed for one hour. Biotinylated se- 


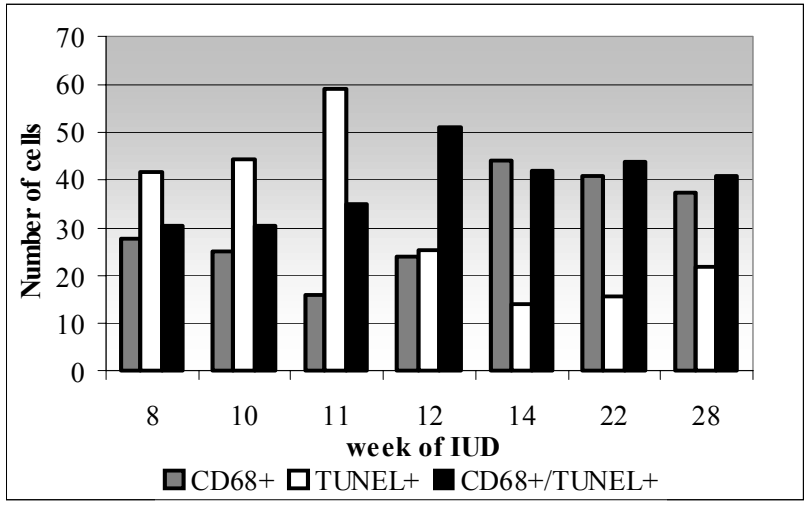

\begin{tabular}{|c|c|c|c|}
\hline week of IUD & CD68+ & TUNEL+ & CD68+/TUN+ \\
\hline $\mathbf{8}$ & 28 & 42 & 31 \\
\hline $\mathbf{1 0}$ & 25 & 44 & 31 \\
\hline $\mathbf{1 1}$ & 16 & 59 & 35 \\
\hline $\mathbf{1 2}$ & 24 & 25 & 51 \\
\hline $\mathbf{1 4}$ & 44 & 14 & 42 \\
\hline $\mathbf{2 2}$ & 41 & 16 & 44 \\
\hline $\mathbf{2 8}$ & 38 & 22 & 41 \\
\hline
\end{tabular}

Graph and Table 1. The number of labelled cells in neogenous zone of human metanephros without any distinction of individual structures. Legend:

IST interstitium

TB primitive tubular structures

MB metanephrogenic blastema

CR renal corpuscle

Blackened cells - localization of the majority of positive cells

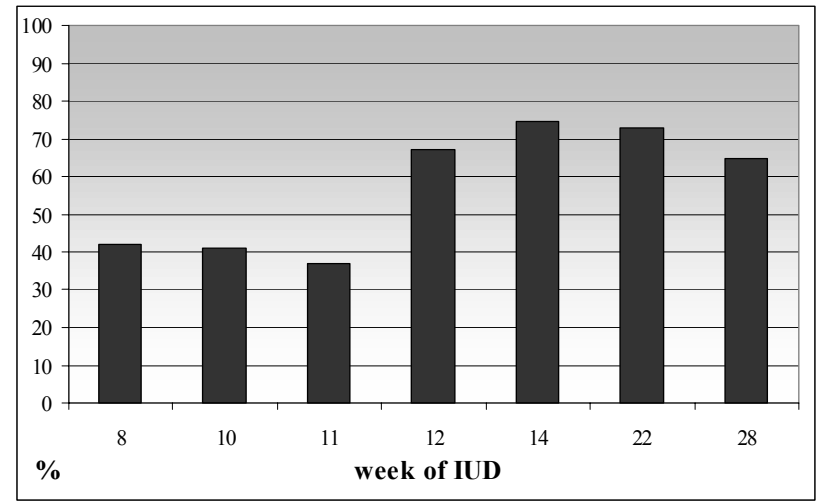

\begin{tabular}{|c|c|}
\hline week of IUD & TUNEL+ \\
\hline $\mathbf{8}$ & 42 \\
\hline $\mathbf{1 0}$ & 41 \\
\hline $\mathbf{1 1}$ & 37 \\
\hline $\mathbf{1 2}$ & 67 \\
\hline $\mathbf{1 4}$ & 75 \\
\hline $\mathbf{2 2}$ & 73 \\
\hline $\mathbf{2 8}$ & 65 \\
\hline
\end{tabular}

Graph and Table 2. The number of apoptotic cells phagocytosed by CD68+ cells in neogenous zone of human metanephros expressed in percents.

Table 2. Distribution of labelled cells in observed structures of neogenous zone in human metanephros.

\begin{tabular}{|c|r|r|r|r|r|r|r|r|r|r|r|r|}
\hline & \multicolumn{4}{|c|}{ CD68+ } & \multicolumn{4}{c|}{ TUNEL+ } & \multicolumn{3}{c|}{ CD68+/TUNEL+ } \\
\cline { 2 - 15 } week of IUD & IST & \multicolumn{1}{|c|}{ TB } & MB & \multicolumn{1}{l|}{ CR } & \multicolumn{1}{|c|}{ IST } & TB & MB & CR & \multicolumn{1}{|c|}{ IST } & TB & MB & CR \\
\hline $\mathbf{8}$ & 0.80 & 0.10 & 0.10 & 0.00 & 0.20 & 0.40 & 0.33 & 0.07 & 0.73 & 0.09 & 0.00 & 0.18 \\
\hline $\mathbf{1 0}$ & 0.89 & 0.00 & 0.11 & 0.00 & 0.56 & 0.06 & 0.31 & 0.06 & 0.91 & 0.00 & 0.00 & 0.09 \\
\hline $\mathbf{1 1}$ & 0.78 & 0.22 & 0.00 & 0.00 & 0.29 & 0.56 & 0.15 & 0.00 & 0.22 & 0.38 & 0.40 & 0.00 \\
\hline $\mathbf{1 2}$ & 0.93 & 0.00 & 0.00 & 0.07 & 0.80 & 0.13 & 0.00 & 0.07 & 0.80 & 0.20 & 0.00 & 0.00 \\
\hline $\mathbf{1 4}$ & 0.68 & 0.16 & 0.00 & 0.16 & 0.17 & 0.67 & 0.00 & 0.17 & 0.83 & 0.11 & 0.00 & 0.06 \\
\hline $\mathbf{2 2}$ & 0.85 & 0.00 & 0.08 & 0.08 & 0.60 & 0.20 & 0.20 & 0.00 & 0.36 & 0.14 & 0.14 & 0.36 \\
\hline $\mathbf{2 8}$ & 0.83 & 0.00 & 0.08 & 0.08 & 0.64 & 0.21 & 0.14 & 0.00 & 0.62 & 0.04 & 0.23 & 0.12 \\
\hline
\end{tabular}

condary anti-mouse antibody and streptavidine-peroxidase conjugate were applied and then the reaction was finished by the incubation of samples first in the substrate of alkaline phosphatase NBT/BCIP (dark-blue precipitate) and then in Vector NovaRed substrate for horseradish peroxidase (red precipitate).

The occurrence of CD68+ cells without engulfed apoptotic bodies (TUNELless cells) (CD68+), ungulfed apoptotic cells (TU + ) and CD68+ cells containing TU+ material were evaluated $(\mathrm{CD} / \mathrm{TU})$. The slides were observed (six observed fields for each section) by the light microscope Olympus under immersion (magn. $\times 1000$ ) which was proved competent especially for evaluation results of double-staining technique. The number of evaluated cells was converted to total number of 100 cells, thus expressed in percents.

\section{RESULTS}

The presence of CD68+ macrophages was proved in the neogenous zone in all the samples having been observed, even in the embryonic period. The majority of them (both $\mathrm{CD} 68+$ and $\mathrm{CD} / \mathrm{TU}$ ) are situated in the mesenchymal interstitium (in the uninduced mesenchyme), often in the vicinity of apoptotic cells. Macrophages rarely occur in metanephrogenic blastema. There were only single CD68+ positive cells in primitive tubular structures and renal corpuscles as well (table 2). The total amount of these cells increased in the $12^{\text {th }}$ week and remained almost on the same level until the $28^{\text {th }}$ week of IUD (Graph and Table 1). The weak CD68 positivity appeared also in primitive tubules in the upper part of differentiating cortex. According to our final results, 


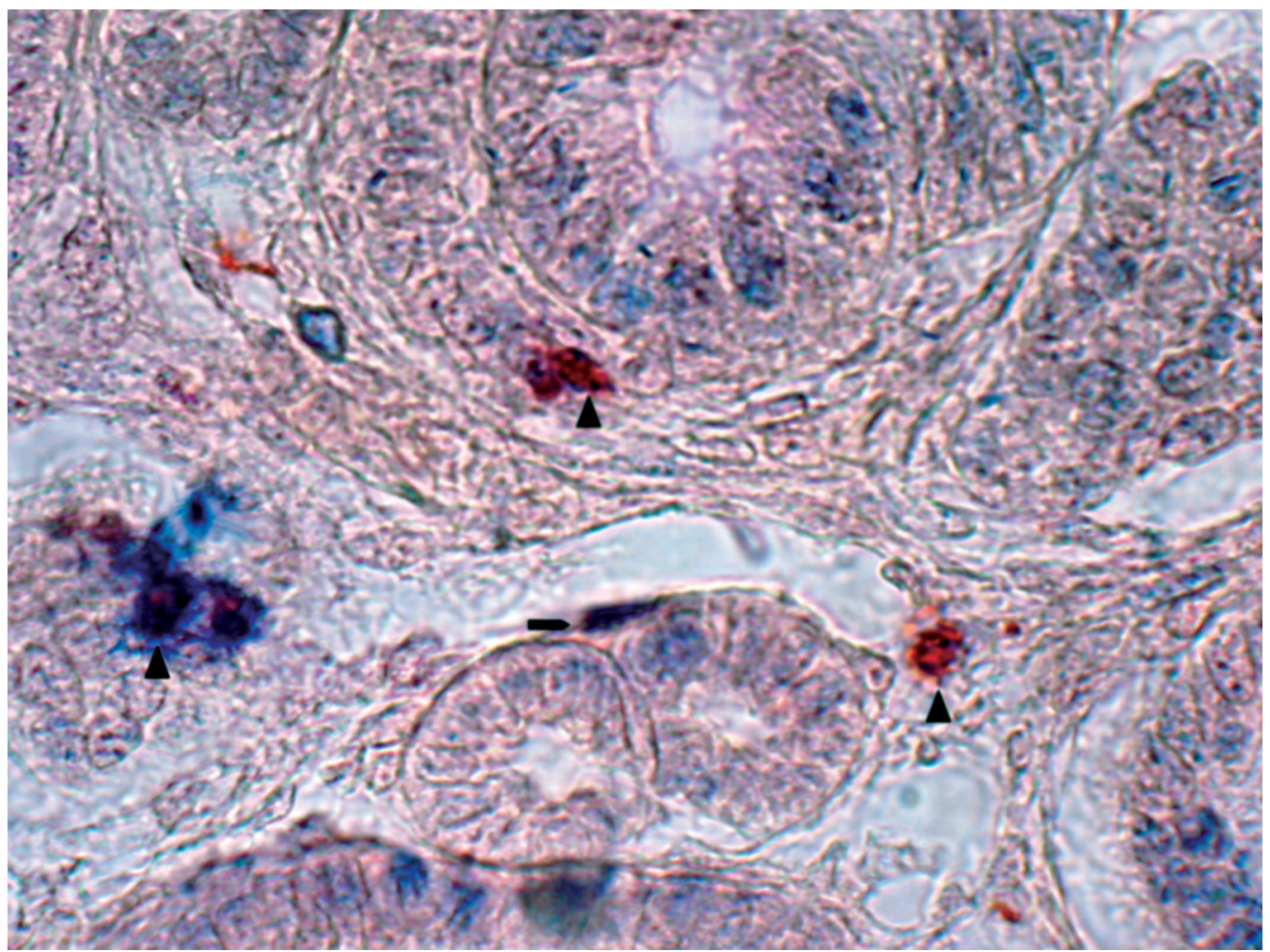

Fig. 1. Neogenic zone of human metanephros: CD68+ macrophages with engulfed apoptotic material (double-staining - triangle arrows) and free apoptotic cell (square arrow). Foetus, $28^{\text {th }}$ week of IUD. Magn. $\times 1000$

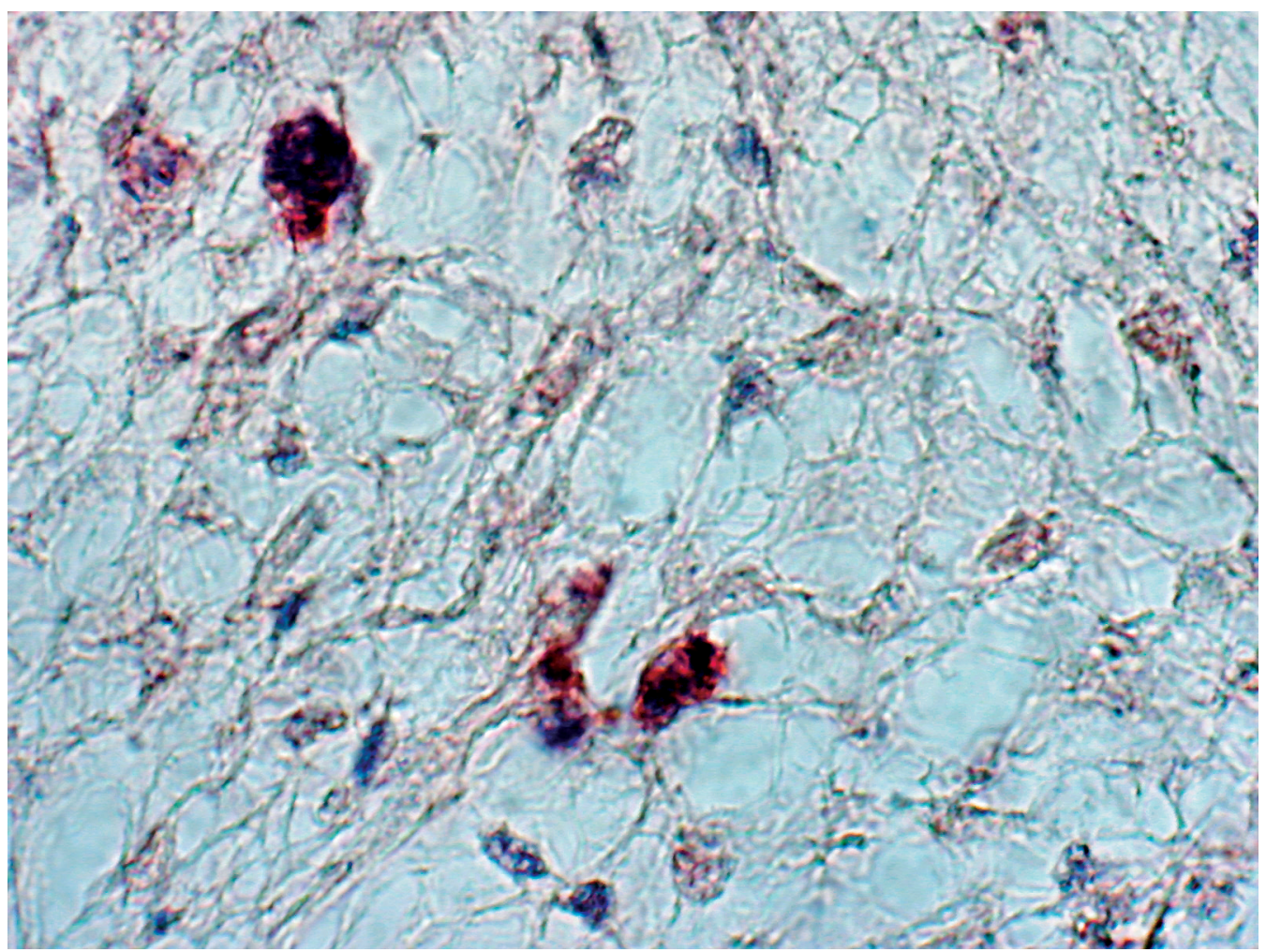

Fig. 2. Neogenic zone of human metanephros: CD68+ macrophages in the mesenchymal interstitium with engulfed apoptotic cells (double-staining). Foetus, $28^{\text {th }}$ week of IUD. Magn. $\times 1000$ 

CD68+ macrophages phagocytosed $37-75 \%$ of apoptotic cells present in neogenous zone and the number of engulfed apoptotic cells increased in the $12^{\text {th }}$ week of the IUD, i.e. in the early fetal period and later it only merely fluctuated (graph and table 2).

\section{CONCLUSIONS AND DISCUSSION}

Yasui et al. ${ }^{7}$ evidenced that $40 \%$ of apoptotic cells in the nephrogenic zone of human fetal kidney $\left(19^{\text {th }}-22^{\text {nd }}\right.$ week of IUD) were surrounded by CD68+ macrophages. According to the investigation of Camp and Martin ${ }^{7}$ and Yasui et al. ${ }^{8}$, the majority of apoptotic residues in murine metanephric kidney occurs in the cytoplasm of macrophages as well. However, the participation of the other cells (non-professional phagocytes) is not excluded as mentioned earlier. In this connexion a question emerges: how can be explained the CD68 positivity of some immature tubules in the upper part of developing cortex and the occurrence of single CD68 + cells in primitive tubules and renal corpuscles in neogenous zone if CD68 is the macrophage marker? Considering that these structures are not fully differentiated and specialized, we can speculate about their being pluripotential (or more than unipotential) and thus about their ability to phagocytose, if necessary. This finding corresponds with the statement of electron microscopic study by Coles ${ }^{9}$ who found out that apoptotic cells were phagocyted by the neighbouring parenchymal cells in the newborn rat kidney. On the other hand, Wood et al. ${ }^{10}$ mention the participation of "stand-in" mesenchymal neighbours phagocyting apoptotic cells in a macrophageless mouse embryo (developing foot-plate was observed)) and they conclude that this redundant mechanism is three times slower in the comparison with the macrophagic one.

Our results confirm the presumption of macrophages being involved in the clearance of apoptotic residues in neogenous zone of human developing kidney in the late embryonal and early foetal periods which is in concordance to above mentioned facts.

\section{ACKNOWLEDGEMENT}

This work was supported by the research project $G A C R$ (304/01/0485).

\section{REFERENCES}

1. Majno Q, Joris I (1995) Apoptosis, Oncosis, and Necrosis. An Overview of Cell Death. Am. J. Pathol., 146, 3-15.

2. Cotter TG (1997) Programmed to Die. The genetic regulation of cell death and its implications. BIOforum International, 1, 8-11.

3. Fadok VA, Savill JS, Haslett C, Bratton DL, Doherty DE, Campbell PA, Henson PM (1992) Different populations of macrophages use either the vitronectin receptor or the phosphatidylserine receptor to recognize and remove apoptotic cells. J Immunol 149, 4029-4035.

4. Wyllie AH, Kerr JFR, Curie AR (1980) Cell death: The significance of apoptosis. Int Rev Cytol 68, 251-306.

5. Hall SE, Savill JS, Haslett C (1990) Fibroblast recognition of aged neutrophils is mediated by the RGD adhesion signal and is modulated by charged particles. Clin Sci 78, $17 \mathrm{p}$.

6. Latker CH, Feinberg RN, Beebe DC (1986) localised vascular regression during limb morphogenesis in the chicken embryo. II. Morphological changes in the vasculature. Anat Rec 214, 410-417.

7. Camp V, Martin P (1996) The role of macrophages in clearing programmed cell death in the developing kidney. Anat. Embryol., 194, 341-348.

8. Yasui M, Tanaka H, Seino Y (1997) The role of tissue-fixed macrophages in apoptosis in the developing kidney. Nephron, 1997, 77, 325-332.

9. Coles HSR, Burne JF, Raff MC (1993) Large-scale normal cell death in the developing rat kidney and its reduction by epidermal growth factor. Development, 118, 777-784.

10. Wood W, Turmaine M, Weber R, Camp V, Maki RA, McKercher SR, Martin P (2000(Mesenchymal cells engulf and clear apoptotic footplate cells in macrophageless PU.1 null mouse embryos. Development $127,5245-5252$. 